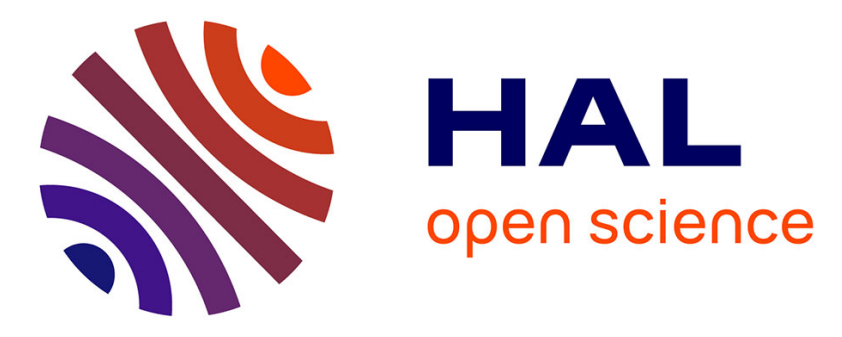

\title{
Study of gallium arsenide on silicon by small angle X-ray scattering
}

V. Vezin, H. Okuda, K. Osamura, Y. Amemiya, K. Kitahara, K. Nakajima

\section{To cite this version:}

V. Vezin, H. Okuda, K. Osamura, Y. Amemiya, K. Kitahara, et al.. Study of gallium arsenide on silicon by small angle X-ray scattering. Journal de Physique IV Proceedings, 1993, 03 (C8), pp.C8381-C8-384. 10.1051/.jp4:1993879 . jpa-00252310

\section{HAL Id: jpa-00252310 https://hal.science/jpa-00252310}

Submitted on 1 Jan 1993

HAL is a multi-disciplinary open access archive for the deposit and dissemination of scientific research documents, whether they are published or not. The documents may come from teaching and research institutions in France or abroad, or from public or private research centers.
L'archive ouverte pluridisciplinaire HAL, est destinée au dépôt et à la diffusion de documents scientifiques de niveau recherche, publiés ou non, émanant des établissements d'enseignement et de recherche français ou étrangers, des laboratoires publics ou privés. 


\title{
Study of gallium arsenide on silicon by small angle $X$-ray scattering
}

\author{
V. VEZIN, H. OKUDA, K. OSAMURA, Y. AMEMIYA, K. KITAHARA and K. NAKAJIMA \\ Osamura Lab., Dept. of Metallurgy, Kyoto Univ., Sakyo-ku, Kyoto 606, Japan
}

\begin{abstract}
\end{abstract}
In order to study the heteroepitaxial growth of gallium arsenide on silicon(100), Small Angle X-ray Scattering (SAXS) experiments have been performed at the synchrotron radiation facility Photon Factory at KEK. The samples studied have been grown by both Atomic Layer Epitaxy and Metal-organic Chemical Vapor Deposition. The two dimensional SAXS patterns present different features depending on the growth technique.

\section{Resume}

Afin d'etudier la croissance heteroepitaxiale de l'arseniure de gallium sur silicium(001), des experiences de diffusion centrale des rayons $X$ ont ete effectuees au rayomnement synchrotron Photon Factory au KEK. Les echantillons etudies ont ete elabores par Atomic Layer Epitaxy et par Metal-Organic Chemical Vapor Deposition. Les courbes bidimensionnelies de diffusion centrale presentent differentes caracteristiques selon la technique de deposition.

\section{Introduction}

Several problems arise during the growth of III-V semiconductors on silicon $/ 1 / 8 / 2 /$ among which the most important are: polar on nonpolar heteroepitaxy which may cause antiphase domains, and a large amount of dislocations due to the lattice mismatch and the difference of thermal expansion coefficients between the epilayer and the substrate. other kinds of defect are sometime observed such as microcracks and amorphous patches at the interface. The most widespread technique to study these materials is Transmission Electron Microscopy (TEM) and especially High Resolution Transmission Electron Microscopy (HRTEM) .

The first Small Angle X-ray Scattering (SAXS) experiments aiming to characterize this kind of material has been performed by okuda et al. $/ 3 /$. The purpose was to study the phase decomposition in Gallium Indium Phosphide grown on Gallium Arsenide on Silicon. It appeared that GaAs on Si itself produced a strong, anisotropic scattering. This was a drawback for the purpose of the experiment but proved that SAXS is a suitable technique to get some informations about GaAs/Si. In the present paper, the origin of the SAXS signal is discussed.

\section{Experiments}

The GaAs layers have been grown on Si(001) substrates of which the surface was few degree misoriented from the (001) plane. Two kinds of sample have been prepared: thin layers $(100 \mathrm{~nm})$ of GaAs grown by Atomic Layer Epitaxy (ALE) and thick layers $(3 \mu \mathrm{m})$ grown by MetalOrganic chemical vapor deposition (MOCVD) on a $100 \mathrm{~nm}$ prelayer of GaAs grown by ALE. Before the SAXg experiments, the silicon substrates have 
been thinned down to have a thickness between 30 and $50 \mu \mathrm{m}$ in order to improve their transmission.

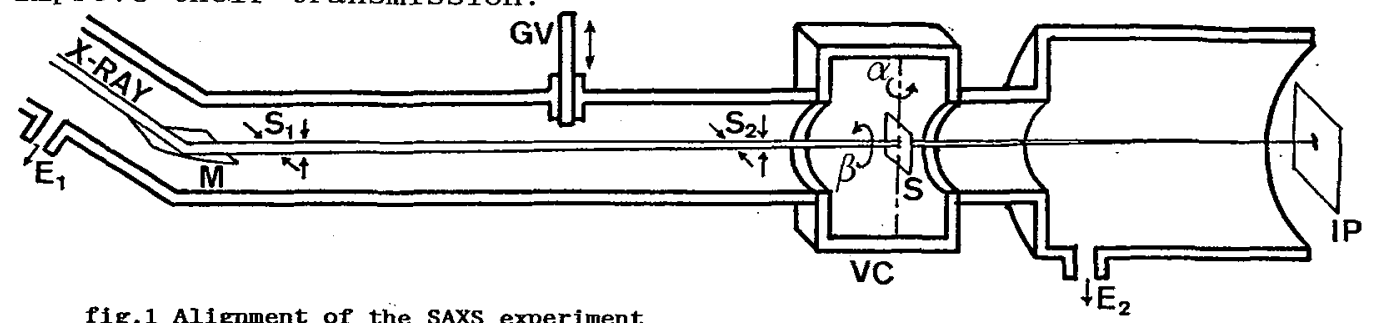

$M$ monochromator, $E_{1} \&$ \& $E_{2}$ evacuation (by rotary pump), $s_{1}$ scatter suppressor slit. $s_{2}$ sample slit, $G V$ vacuum gate valve, ve vacuum chamber, $S$ sample, $\alpha$ rotation around the vertical axis, $\beta$ rotation around the direction normal to surface of the sample, IP imaging plate.

The experiments were performed at the beam line 15A at the Photon Factory in KEK (Tsukuba), in transmission mode. The camera configuration is displayed in fig.1. The samples were mounted on a two axis of rotation sample holder which allowed a rotation $\alpha$ around the vertical axis perpendicular to the $\mathrm{X}$-ray beam and a rotation $\beta$ around the normal to the surface of the sample. The two dimensional SAXS data were collected using Imaging Plates/4/. In order to obtain a good signal/noise ratio, the whole $X$-ray path was in vacuum. The wave length of the $\mathrm{X}$-ray beam was $1.5 \AA$.

\section{results and discussions}

The SAXS patterns present two kinds of features: (i) a diffuse halo around the direct beam and (ii) two streaks parallel to the crystallographic directions [110] and [110] of the sample when the $X-$ ray beam is parallel to the normal of the surface of the specimen. The SAXS signal provided by the silicon substrate without epilayer did not depart significantly from the background. Both features (i) and (ii) will be discussed separately.

-(i) - The contour map of the intensity for a GaAs/Si sample grown by ALE, after subtraction of the background (i.e. the intensity obtained without sample) is shown in fig.2. The intensity is reported in arbitrary unit and $\mathrm{q}_{x}$ and $\mathrm{q}_{\mathrm{y}}$ are the components of the scattering vector $q(q=4 \pi / \lambda \cdot \sin (\theta)$ where $2 \theta$ is the scattering angle $)$ in the plane perpendicular to the X-ray beam. $\mathrm{q}_{\mathrm{y}}$ is parallel to the axis of the rotation $\alpha$. The profile is isotropic for $\alpha=0^{\circ}$ ( $\mathrm{fig.2.a}$ ) there is therefore no special orientation in the plane of the interface. When $\alpha$ increases, $\left(\alpha=60^{\circ}\right.$ in fig.2.b), the pattern is elongated in the direction perpendicular to the axis of rotation. This observation does not depend on $\beta$. Thus, the fluctuation of the electronic density responsible for the SAXS signal is more extended in the plane of the interface than in the direction of the normal to the surface. Since the intensity is of the same order of magnitude for both kinds of sample, the number of scatterers does not increase when the thick layer grown by MOCVD is deposited on the ALE grown prelayer, therefore, the origin of the scattering is should be situated at the interface. As shown in fig.3, the signal is not strongly affected by the misorientation of the silicon substrate (then the density of steps at the interface). The crystallographic defects, namely antiphase boundary, stacking faults and dislocation can't be accountable for such a scattering. two candidates may be considered. The first possibility is some amorphous or misoriented patches observed by HRTEM at the interface by Koch et al $/ 5 /$ and Hull et al $/ 6 /$. The nature of these defects is not clear but there geometrical characteristics (i.e. flat lens or platelet) are compatible with the SAXS signal described above. The second possibility is diffusion at the interface. As shown in fig.4, the Rutherford Back Scattering (RBS) spectrum of a thin ALE grown sample presents a shoulder at the edge of the silicon 

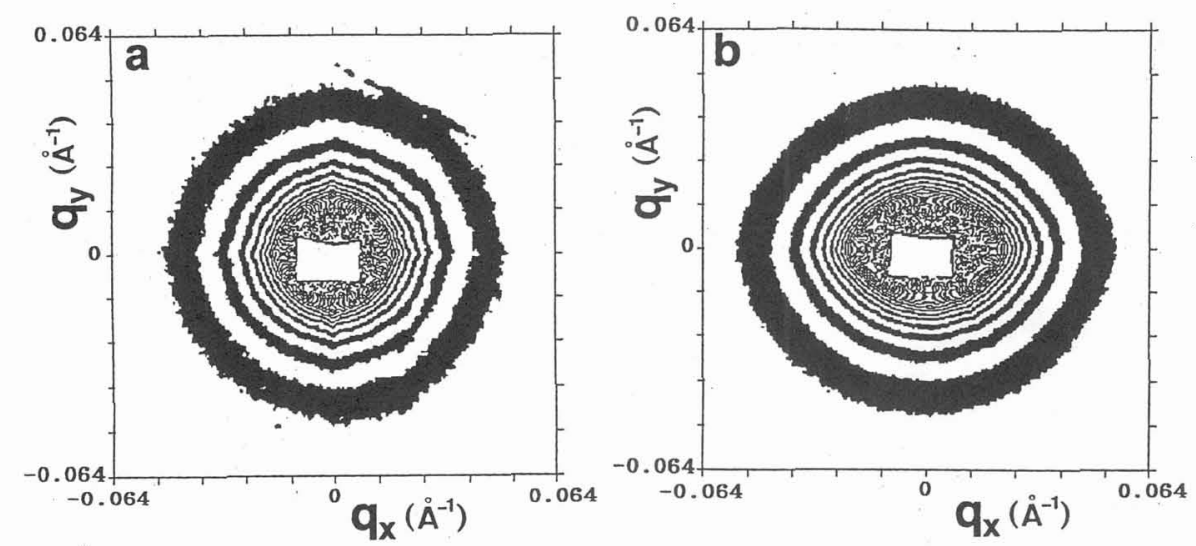

fig.2 SAXS patterns for a $100 \mathrm{~nm}$ thick sample of GaAs/S1 grown by AlE with (a) $\alpha=0$ : , $\beta=0^{\circ}$ and (b) $\alpha=60^{\circ}, \beta=0^{\circ}$.

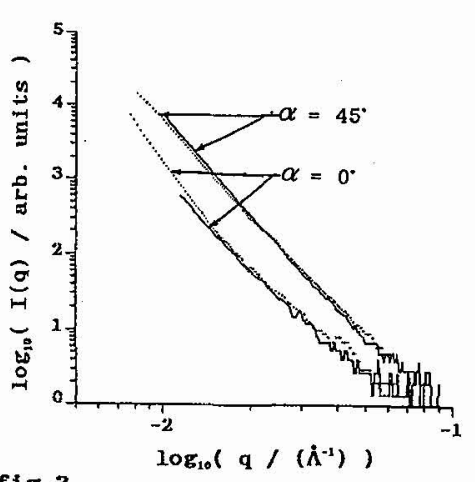

fig.3

SAXS curves for $100 \mathrm{~nm}$ thick samples of GaAs/S1 grown by ALE on silicon substrates oriented 2 off toward $\langle 110\rangle$ (continuous I1nes) and $3^{*}$ off toward $\langle 110\rangle$ (points). $\beta=0^{\circ}$ for all curves and the directions in the reciprocal space of the one dimentional cuts are $q y=q x$ for $\alpha=0^{\circ}$ and qy $=0$ for $\alpha=45^{\circ}$.

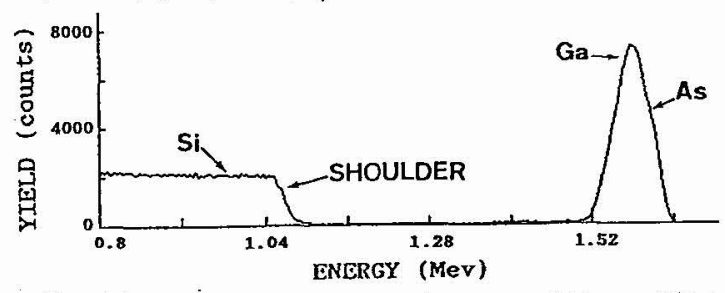

fig.4 RBS spectrum obtained with a $100 \mathrm{~nm}$ thick sample of GaAs/Si grown by ALE.

contribution to the curve, furthermore, in the RBS spectra obtained both with the incident ion beam in a random direction and in the channeling direction $\langle 100\rangle$, the presence of other elements than $\mathrm{Ga}$, As and Si could not be identified. These observations can be due to inhomogeneities of the thickness crossed through GaAs by the incident ions (i.e. irregular thickness of the GaAs layer or ups an downs at the interface) but in such a case the difference of thickness crossed by the ions in GaAs should be of about $10 \mathrm{~nm}$ which is quite improbable. A more realistic possibility is intermixing or interdiffusion at the interface. this possibility is furthermore supported by several observations $/ 7 / 8 / 8 /$, using Secondary Ion Mass Spectroscopy, of clusters of silicon in GaAs layers grown by MOCVD on Si. Further investigations are necessary to determine with certitude which explanation is correct. However this part of the SAXs pattern promises to be a useful tool for the study of the epitaxial deposition of GaAs on $\mathrm{Si}$.

-(ii)- The streaks parallel to $[110]$ and $[1 \overline{1} 0]$ mentioned above are clearly visible in the contour map of the intensity obtained with a specimen grown by MOCVD, displayed in fig.5. In fig.5.a $\alpha \doteq \beta=0^{\circ}$ and in fig.5.b $\alpha=0^{\circ}$ and $\beta=45^{\circ}$. Both streaks disappear when $\alpha$ exceeds about $2^{\circ}$. They cross each other at the origin of the reciprocal space, but they are not necessarily symmetrical with respect to the origin. Note that in $\mathrm{fig} 5$, the angular origin chosen for $\alpha$ is taken arbitrarily. If one consider the position for which the horizontal streak is symmetrical, would be equal to $0.25^{\circ}$. With such a choice for the origin, the streak for, say, $\alpha=-1^{\circ}$ is the mirror image of the one for $\alpha=+1^{\circ}$. A careful observation of the pattern of fig.2.a reveals that these streaks are also present in the case of thin ALE 
grown samples, but in this case they are much weaker. Several kinds of possible defects have been considered to explain the origin of this scattering /9/ without really conclusive outcomes. Given the dependence on the thickness of the epilayer and the dissymetry with respect to the origin of the steaks, this part of the SAXS pattern should be due or to some dynamical effect or to some cristallin defect.
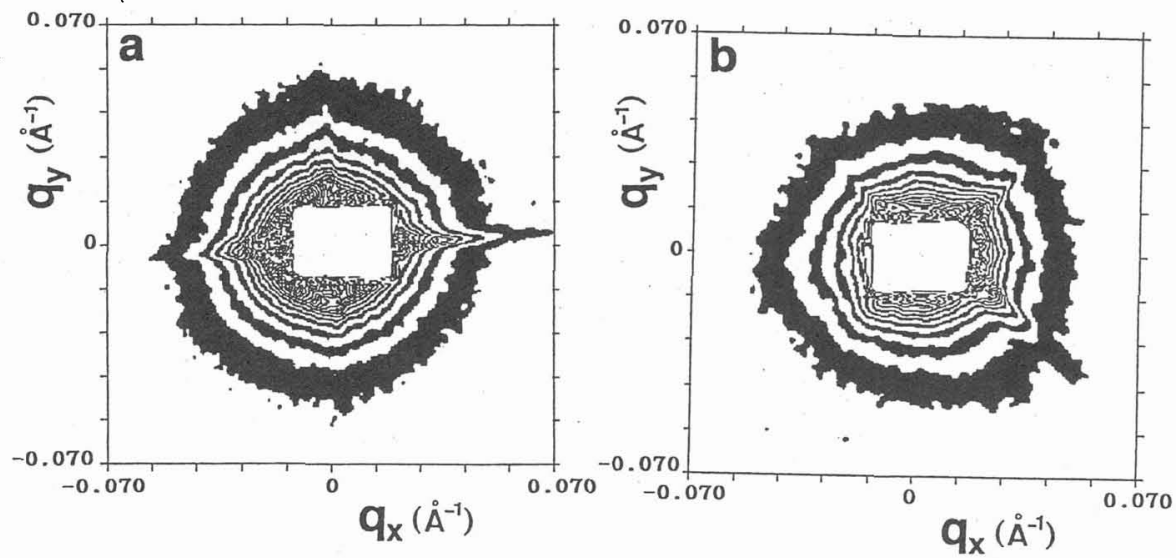

fig.5 SAXS patterns for a $3 \mu \mathrm{m}$ thick sample of GaAs/S1 grown by MOCVD with (a) $\alpha=0^{\circ}, \beta=0^{\circ}$ and (b) $\alpha=0^{\circ}$ and $\beta=45^{\circ}$.

\section{Concluding remarks}

Before to start a quantitative study of the heteroepitaxial growth of GaAs/Si it is necessary to elucidate some questions about the origin of the scattered intensity. However, two main features have been observed. One is a signal distributed all around the direct beam which is due to interfacial defects. This point deserves to be further investigated since there are few other techniques adapted for the characterization of these defects. The other point is a pair of streaks in [110] and [110] directions when the X-ray beam is perpendicular to the surface of the sample. It is now difficult to say which outcome can be expected from it for the study of the growth of GaAs/Si, but, from experimental point of view, it is interesting to carry on with the investigation of this profile.

Acknowledgment: Science.

V.Vezin is sponsored by the Japan Society for the Promotion of

\section{References :}

/1/ S.Mahajan, Progress in Material Science, 33, (1989), 1-84.

/2/ S.F.Fang, K.Adomi, S.Iyer, H.Morkoc, H.Zabel, C.Choi, N.otsuka, J.Appl.Phys., 68(7), (1990), R31-R58.

/3/ H.okuda, K.Osamura, S.Komiya, Y.Amemiya, photon factory activity report, 8, (1990), 329.

/4/ Y.Amemiya, Synchrotron radiation in biophysics, 261-273.

/5/ S.M.Koch, S.J.Rosner, R.Hul1, G.W.Yoffe, J.S.Harris, J.Crys.Growth, 81, (1987), 205-213.

/6/ R.Hull, S.J.Rosner, S.M.Koch, J.S.Harris Jr., Appl.Phys.Lett., 49(25), (1986), 1714-1716.

/7/ S.J.Pearton, D.L.Malm, L.A.Heimbrook, J.Kovalchick, C.R.Abernathy, R.Caruso, S.M.Vernon, V.E.Haven, Appl.Phys.Lett 51(9), (1987), 682688 .

/8/ A.Freundlich, A.Leycuras, J.C.Grenet, C.Grattepain, Appl.Phys.Lett. $53(26),(1988), 2635-2637$.

/9/ H.okuda, V.Vezin, M.Nagao, K.Osamura, Y.Amemiya, Photon Factory activity report, 9 (1991). 